\title{
Antioxidants, Microbial Load and Heavy Metal Contents of Some Sachet Tomato Paste Obtained in Lagos State, Nigeria
}

\author{
${ }^{1}$ ELEYOWO, OO; ${ }^{2 *}$ AMUSA, OD \\ ${ }^{1}$ Department of Science Laboratory Technology, Lagos State Polytechnic, Nigeria \\ ${ }^{* 2}$ Department of Cell Biology and Genetics, University of Lagos, Nigeria \\ *Corresponding author's email: odamusa@unilag.edu.ng
}

\begin{abstract}
Tomato paste is fast becoming first choice for many homes in cooking while meeting up with their busy schedules in a cosmopolitan city like Lagos State, Nigeria. The study was aimed at evaluating the antioxidant contents, microbial load and heavy metal contents of both unprocessed and processed tomato products. $\beta$-carotene, lycopene and vitamin $\mathrm{C}$ contents were analysed accordingly on selected sachet tomato paste. Microbial colony counts were done using both nutrient agar and potatoes dextrose agar. Heavy metals from sampled tomato products were done using Atomic Absorption Spectrometry. The study observed $\beta$-carotene ranged between $0.02-0.52 \mathrm{mg} / \mathrm{g}$, lycopene ranged between $0.12-0.56 \mathrm{mg} / \mathrm{g}$ and vitamin $\mathrm{C}$ contents of ranged between $12.50-75.0 \mathrm{mg} / \mathrm{mL}$. These were more than WHO/FAO and FEPA recommendations. All tomatoes samples showed microbial load higher than limits allowable. Bacillus sp., Salmonella sp., Aspergillus sp. were predominantly isolated from sampled processed tomato products. Cadmium contents were above the permissive limit in some of the tomato paste products. Copper, zinc, lead, nickel, chromium and iron were not detected in all samples evaluated. The study showed few processed tomato products were safe for consumption. Hence, monitoring by regulatory agencies for consumer safety regulations is highly recommended on processed tomato producers.
\end{abstract}

\section{DOI: https://dx.doi.org/10.4314/jasem.v25i4.23}

Copyright: Copyright $(2) 2021$ Eleyowo and Amusa. This is an open access article distributed under the Creative Commons Attribution License (CCL), which permits unrestricted use, distribution, and reproduction in any medium, provided the original work is properly cited.

Dates: Received: 14 February 2021; Revised: 26 March 2021; Accepted: 12 April 2021

Keywords: Antioxidant, Heavy Metals, Microorganisms, Tomato

Tomato (Solanum lycopersicum L.) belongs to the family Solanaceae. It is a horticultural crop of great interest, being widely consumed either fresh or processed such as tomato juice, soup, paste, puree, ketchup, sauce and salsa (Ray et al., 2011). Botanically classified as a fruit, although, some think of it as a vegetable (USDA, 2013), it is the third most cultivated and world widely grown vegetable crop.

The household consumption of tomatoes is on high increase worldwide as it is very rich in vitamins, minerals, dietary fibre and protein (Wogu and Ofuase, 2014). Tomato is consumed all year round in various forms, being very appetizing, refreshing and pleasing to taste (Famurewa and Raji, 2011). Its consumption is currently considered as a nutritional indicator of good dietary habit and healthy life style. This fruit has undoubtedly assumed the status of a food with functional properties, considering the overwhelming epidemiological evidence for its capacity to reduce the risk of certain types of cancers, incidence of cardiovascular diseases, prostate, gastrointestinal and epithelial cell cancers through its antioxidant properties (Buculei et al., 2011). Nigeria is the largest producer of tomatoes in Sub-Saharan Africa as it is an important component of the daily diet of Nigerians. It is consumed in diverse ways, including raw, as an ingredient in soup, many dishes, sauces, salads, and drinks. It is also used in producing pastes, and dehydrated or frozen products (Adetoro et al., 2015). However, the busy lifestyles and changing of consumer food habits in metropolitan cities like Lagos State have resulted in a growing demand of ready to eat, safe and convenient foods. Most families have less time to cook at home and tend to patronise fast foods to the detriment of their health. Since most homes rely on tomato paste products for domestic dishes, there is the need to not only to ascertain that these tomato alternatives are nutritionally the similar but also a safe alternative. Hence, the objectives of the study were to evaluate the antioxidant quality, microbial load and heavy metal contents in some commonly consumed sachet tomato paste.

\section{MATERIALS AND METHODS}

Sample collection: The study includes, eight tomato processed products, dried and raw tomatoes randomly collected from the Ikorodu market, Lagos state (Table $1)$. 
Determination of $\beta$-carotene: $\beta$-carotene in the tomato samples were analysed according to the method of Nagata and Yamashita (1992). $0.1 \mathrm{~g}$ of sample was weighed and dissolved in acetone and hexane in the ratio of 40:60. $5 \mathrm{~mL}$ of the solution was taken and filtered. The absorbent was read at 453, 505 and 663 $\mathrm{nm}$. $\beta$-carotene was then calculated following the formula;

$$
\begin{gathered}
\beta \text {-carotene }=0.216\left(A_{663}\right)-0.304\left(A_{505}\right) \\
+0.452\left(A_{453}\right)
\end{gathered}
$$

Table 1: Sample products used for the study

\begin{tabular}{llll}
\multicolumn{4}{c}{ Table 1: Sample products used for the study } \\
\hline s/n & Name & ID & Category /Form \\
\hline 1 & Hanno & Han & Processed \\
2 & Ric-giko & Rgk & Processed \\
3 & Lenna & Len & Processed \\
4 & Gino & Gin & Processed \\
5 & Vitali & Vit & Processed \\
6 & Tasty tom & Ttm & Processed \\
7 & Sonia & Son & Processed \\
8 & Heinz & Hez & Processed \\
9 & Dry tomatoes & DTm & Dry \\
10 & Fresh tomatoes & FTm & Fresh \\
\hline
\end{tabular}

Determination of Lycopene: Lycopene in the tomato samples was extracted using hexane: ethanol: acetone $(2: 1: 1)(\mathrm{v} / \mathrm{v})$ mixture following the method of Adejo $e t$ al., (2015). $0.001 \mathrm{~g}$ of sample was dissolved in $1 \mathrm{~mL}$ of distilled water and vortexed in a water bath at $30^{\circ} \mathrm{C}$ for $1 \mathrm{hr}$. Then, $8.0 \mathrm{~mL}$ of hexane, ethanol and acetone (ratio 2:1:1) was added, capped and vortexed again, followed by incubation in a dark cupboard for $60 \mathrm{~min}$. $1 \mathrm{~mL}$ of distilled water was added to each sample and vortexed once more then allowed to stand and separate into phases. Care was taken to ensure that bubbles formed had fully disappeared. The cuvette was rinsed with the upper layer of one of the blank samples before using more fresh blank samples to zero the spectrophotometer at $503 \mathrm{~nm}$. Absorbance of the upper layers of the lycopene samples were read at $503 \mathrm{~nm}$. Lycopene levels of the extracts were then calculated using:

$$
\operatorname{mg~LP}=\frac{A_{503} \times 537 \times 8 \times 0.55}{0.10 \times 172}
$$

Where LP = mg Lycopene per $100 \mathrm{~g}$ of sample, 537 $\mathrm{g} / \mathrm{mole}$ is the molecular weight of lycopene, $8 \mathrm{~mL}$ is the volume of mixed solvent, 0.55 is the volume ratio of the upper layer to the mixed solvents, $0.10 \mathrm{~g}$ is the weight of tomato added, and $172 \mathrm{mM}^{-1}$ is the extinction coefficient for lycopene in hexane.

Determination of Vitamin C: This was determined according to the method of Adejo et al., (2015). Standard ascorbic used in the DPPH solution of methonolic DPPH calibration plot (Antioxidant activity) (above) was used, and the Ascorbic content was calculated as:

$$
\begin{gathered}
\text { mg Ascorbic acid per } 100 \mathrm{~g} \text { of sample } \\
=\frac{100 \times(\mathrm{V} \times \mathrm{T})}{\mathrm{W}}
\end{gathered}
$$

Where $\mathrm{V}=\mathrm{mL}$ dye used for titration of aliquot of diluted sample, $\mathrm{T}=$ Ascorbic acid equivalent of dye solution expressed as $\mathrm{mg} / \mathrm{mL}$ of dye, $\mathrm{W}=$ gram of sample aliquot that will titrated. Values were converted and presented in $\mu \mathrm{g} / \mathrm{mL}$ (Adejo et al., 2015)

Microbial evaluation of tomato product samples: Microbial evaluation was done according to Eleyowo et al., (2016). The following media which include Nutrient Agar (NA) and Potato Dextrose Agar (PDA) were used for the enumeration of microbial counts. They were prepared according to the manufacturer's guide and sterilized in an autoclave at $121{ }^{\circ} \mathrm{C}$ for 15 min. Microbial analyses were carried out in the Microbiology Laboratory, Department of Science Laboratory Technology, Lagos State Polytechnic, Lagos State. The pour plate method was used to cultivate serially diluted portions of the tomato product samples under investigation. Enumeration was carried out on NA and PDA for bacteria and fungi counts respectively. Triplicate plates of appropriate dilutions were prepared. The NA plates were incubated at $37{ }^{\circ} \mathrm{C}$ for $24-48 \mathrm{hr}$ for bacteria growth while PDA plates were incubated at room temperature $\left(28 \pm 2{ }^{\circ} \mathrm{C}\right)$ for 48 $-72 \mathrm{hr}$ for fungal growth. The developed microbial colonies were counted and computed as colony forming units per gram (cfu/g) of each sample, respectively. The colonies were isolated and purified for further identified with biochemical reactions which include gram's staining, coagulase test, catalase test and microscopy accordingly (Eleyowo et al., 2016).

Heavy metals evaluation: The method of Ademoroti (1996) was used to determine heavy metal levels in sampled tomato products. $1 \mathrm{~g}$ of each of the tomato product sampled was measured into a $250 \mathrm{~mL}$ conical flask and about $2-3 \mathrm{~g}$ of glass beads. $5 \mathrm{~mL}$ of aqua redia $\left(\mathrm{HNO}_{3}: \mathrm{HCl}, 1: 3\right)$ was then added to the content inside the flask and mixed thoroughly. The flask, with the content was later placed on a hot plate to heat for some minutes to evaporate to about $15 \mathrm{~mL}$. The flask was then cooled and another $5 \mathrm{~mL}$ of conc. $\mathrm{HNO}_{3}$ was added. The flask was covered with watch glass. Few $\mathrm{mL}$ of conc. $\mathrm{HNO}_{3}$ was added dropwise until the solution appeared light coloured and clear. The flask and watch glass were washed with distilled water and the sample was filtered into the Atomic Absorption Spectrometry (AAS) bottle ready for ASS analysis (Ademoroti, 1996). Metals evaluated include copper, 
zinc, lead, cadmium, potassium, nickel, sodium silver, calcium, chromium and iron. The resulting concentrations of each metal evaluated was compared with the help of WHO/FAO and FEPA maximum permissible limits.

Statistical analysis: All analysis was done using SPSS Statistics v 23 software package.

\section{RESULTS AND DISCUSSION}

$\beta$-carotene, lycopene and vitamin $C$ contents of sampled tomato paste products: Tomatoes and its products are important contributors of lycopene, $\beta$ carotene, vitamin $\mathrm{C}$ and phenolics in food consumed by most people (Usha et al., 2013).

Antioxidant evaluation among tomato paste samples showed that $\beta$-carotene, lycopene and vitamin $\mathrm{C}$ contents were higher than both WHO/FAO and FEPA recommended levels. Only Len $(0.45 \mathrm{mg} / \mathrm{g})$ and Gin $(0.52 \mathrm{mg} / \mathrm{g})$ showed $\beta$-carotene levels significantly higher than the raw tomatoes $(0.29 \mathrm{mg} / \mathrm{g})$ while $\mathrm{Rgk}$, Vit, Ttm, Son, Hez and DTm had $\beta$-carotene significantly lower when compared to the raw tomatoes (Table 2).

Lycopene contents for all the tomato paste products sampled were significantly higher than both dry and raw tomatoes. However, lycopene contents in both dry and raw tomato samples did not significant differ (Table 2). Lycopene contents found in fresh tomatoes used in this study $(0.05 \mathrm{mg} / \mathrm{g})$ was lower than the report of Adejo et al., (2015) who reported a lycopene content of $0.158 \mathrm{mg} / \mathrm{g}$ in the raw tomatoes they used.
Also, process tomato pastes were higher in lycopene contents than that observed by Adejo et al., (2015) in their study.

Vitamin C content was highest in dried tomato sample in the study. This might be due to its concentrate nature resulting from water dehydrated. All tomato paste samples except $\mathrm{Ttm}$ were significantly higher in Vitamin $\mathrm{C}$ contents than the raw tomatoes evaluated (Table 2). This might have resulted from fortification of this antioxidant during processing in the processed samples compare to the raw tomatoes. Vitamin C contents from this study was however lower (12.5 $\mathrm{mg} / \mathrm{mL}$ ) than that reported by Adejo et al., (2015) in fresh tomatoes $(20.74 \mathrm{mg} / \mathrm{mL})$. Also, Varietal differences in Vitamin $\mathrm{C}$ contents from different regions have been reported (Juroszek et al., 2009; Ilahy et al., 2011; Kotkov et al., 2011). This varietal difference may be attributed not only to genotypic differences but also environmental influence.

Dumas et al. (2003) in their study also suggested several other factors such as the ripening stage, cultivation practices (water availability, mineral nutrients), and climatic factors (mostly light and temperature) contributing to the differences observed.

However, the presence of more $\beta$-carotene, lycopene and vitamin $\mathrm{C}$ contents in processed tomato products than the fresh samples of tomatoes evaluated on this study shows an improvement in nutritional contents of processed tomatoes to unprocessed tomatoes. These were also well above the WHO/FAO recommended intake.

Table 2: Antioxidant content of tomato samples evaluated

\begin{tabular}{lllll}
\hline s/n & ID & $\begin{array}{l}\beta \text {-carotene } \\
(\mathrm{mg} / \mathrm{g})\end{array}$ & $\begin{array}{l}\text { Lycopene } \\
(\mathrm{mg} / \mathrm{g})\end{array}$ & $\begin{array}{l}\text { Vitamin C } \\
(\mathrm{mg} / \mathrm{ml})\end{array}$ \\
\hline 1 & Han & $0.27^{*}$ & $0.21^{\dagger *}$ & $50.00^{\dagger *}$ \\
2 & Rgk & $0.02^{*}$ & $0.25^{\dagger *}$ & $50.00^{\dagger *}$ \\
3 & Len & $0.45^{\dagger *}$ & $0.33^{\dagger *}$ & $25.00^{\dagger *}$ \\
4 & Gin & $0.52^{\dagger *}$ & $0.56^{\dagger *}$ & $75.00^{\dagger *}$ \\
5 & Vit & $0.18^{*}$ & $0.19^{\dagger *}$ & $25.00^{\dagger *}$ \\
6 & Ttm & $0.12^{*}$ & $0.25^{\dagger *}$ & $12.50^{*}$ \\
7 & Son & $0.06^{*}$ & $0.15^{\dagger *}$ & $25.00^{\dagger *}$ \\
8 & Hez & $0.13^{*}$ & $0.12^{\dagger *}$ & $25.00^{\dagger *}$ \\
9 & DTm & $0.03^{*}$ & $0.02^{*}$ & $100.00^{\dagger *}$ \\
10 & FTm & $0.29^{*}$ & $0.05^{*}$ & $12.50^{*}$ \\
\hline & & & & \\
& WHO/FAO & 0.0005 & 0.003 & 0.05 \\
& FEPA & 0.0005 & 0.003 & 0.05
\end{tabular}

WHO/FAO and FEPA values are recommended levels in $\mathrm{mg} / \mathrm{g} /$ day; ${ }^{\dagger}$ values significantly higher from fresh tomatoes; * values significantly higher than permissive limits

Microbial load of sampled tomato paste products: Varied degree of microbial contamination were observed among sample tomato products with majority having microbial load above permissive level. Samples of processed tomato product except
Henz tomato product showed total bacterial count above permissive level (WHO limits $=10^{2} \mathrm{cfu} / \mathrm{g}$ ). The highest microbial load was obtained from dried tomato samples. Total fungi count (TFC) was above permissive limit for all sampled products except Gino 
tomato product $(\mathrm{WHO}$ limits $=0 \mathrm{cfu} / \mathrm{g})$. The highest TFC was obtained in fresh tomatoes (Fig 1).

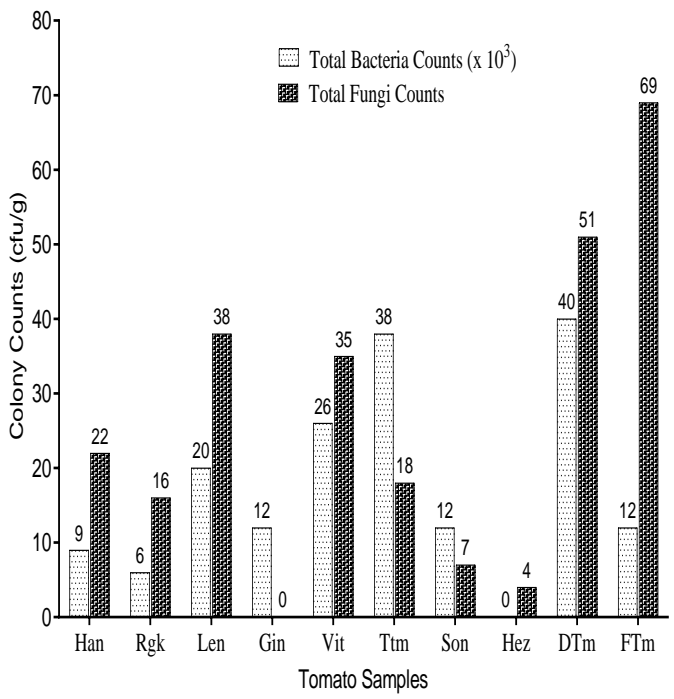

Fig 1: Microbial load of sampled tomato products evaluated

Table 3. Identified microbes in tomato products

\begin{tabular}{|c|c|c|}
\hline $\mathrm{s} / \mathrm{n}$ & ID & Identified microorganisms \\
\hline 1 & Han & $\begin{array}{l}\text { Bacillus sp., Streptococcus sp., } \\
\text { Aspergillus } s p .\end{array}$ \\
\hline 2 & Rgk & Streptococcus sp., Aspergillus sp. \\
\hline 3 & Len & Streptococcus sp., Aspergillus sp. \\
\hline 4 & Gin & Salmonella sp., \\
\hline 5 & Vit & Salmonella sp., Aspergillus sp. \\
\hline 6 & Ttm & Bacillus sp., Aspergillus sp. \\
\hline 7 & Son & $\begin{array}{l}\text { Bacillus sp., Pseudomonas sp., } \\
\text { Pseudomonas sp. }\end{array}$ \\
\hline 8 & Hez & Aspergillus sp. \\
\hline 9 & DTm & $\begin{array}{lll}\text { Streptococcus } & s p ., \quad \text { Bacillus } & \text { sp., } \\
\text { Salmonella sp., Aspergillus sp. } & \\
\end{array}$ \\
\hline 10 & FTm & $\begin{array}{l}\text { Streptococcus sp., Bacillus sp., } \\
\text { Staphylococcus sp., Aspergillus sp. }\end{array}$ \\
\hline
\end{tabular}

These prevalent level of microbial growth present may be due to microbial fruit infections during crop cultivation, harvesting, post-harvest handling at processing, storage, transportation and packaging, and distribution (loading and offloading) at various channels and selling outlets of which bacteria and fungi are prevalent as suggested by Fung (2009), Akinyele and Akinkunmi, (2012), Adejo et al., (2015).

Also, tomato fruit being succulent with about $80 \%$ water content, low $\mathrm{pH}$, highly rich nutrients elements and sugars, could serve as suitable medium for microbial growth (Singh and Sharma, 2007; Muhammad et al., 2004). The presence of minimal microbial load in Henz tomato product showed that microbial load in processed tomato product when adequate safety procedures are followed in product production. Predominant microbes in the study were Bacillus sp., Streptococcus sp., and Aspergillus sp. (Table 3). This corroborates with the works of Bashir et al. (2016).

Heavy metal content in sampled tomato paste products: In this present study, zinc, lead, nickel and chromium were not detected in all sampled tomato paste products, dried and raw tomatoes evaluated (Table 4). This does corroborate with the report of Adegbola (2013) who showed fresh tomato collected at Ibadan contained copper, zinc, lead, chromium, nickel and iron beyond WHO permissive and Dallatu et al., (2013) reported that tomato paste from North Central region of the country contained copper, zinc, lead and Nickel contents beyond permissive limits. Copper was not detected in all samples evaluated except in Henz tomato paste and this was below permissive limit. Cadmium was detected in all samples beyond both WHO/FAO and FEPA permissive limits except in Ttm, Son and DTm. Only Rgk (Table 4). The presence of cadmium content in most of the tomato paste products and fresh tomatoes more than permissive limits calls for concern. The high level of this metal in fresh food may be connected with environmental factors such as polluted soil and polluted waste water used for irrigation of the farms.

Table 4. Heavy metals analysis of tomato samples evaluated for the study

\begin{tabular}{|c|c|c|c|c|c|c|c|c|c|c|c|c|c|}
\hline \multirow{2}{*}{$\mathbf{s} / \mathbf{n}$} & \multirow{2}{*}{ ID } & $\mathrm{Cu}$ & $\mathrm{Zn}$ & $\mathrm{Pb}$ & $\mathrm{Cd}$ & $\mathrm{K}$ & $\mathrm{Ni}$ & $\mathrm{Na}$ & $\mathrm{Ag}$ & $\mathrm{Ca}$ & $\mathrm{Cr}$ & $\mathrm{Mn}$ & $\mathrm{Fe}$ \\
\hline & & \multicolumn{12}{|l|}{$\mu \mathrm{g} / \mathrm{g}$} \\
\hline 1 & Han & $\mathrm{ND}$ & ND & $\mathrm{ND}$ & 1.03 & 33.58 & $\mathrm{ND}$ & 10.87 & 0.07 & 12.77 & ND & 0.01 & $\mathrm{ND}$ \\
\hline 2 & Rgk & ND & ND & ND & 1.85 & 31.54 & ND & 17.97 & 0.16 & 26.56 & ND & 0.25 & 3.50 \\
\hline 4 & Gin & ND & ND & ND & 0.76 & 32.54 & ND & 7.64 & 0.11 & 14.07 & ND & 0.13 & ND \\
\hline 5 & Vit & ND & ND & ND & 0.23 & 33.64 & ND & 15.61 & 0.13 & 21.18 & ND & 0.05 & ND \\
\hline 6 & $\mathrm{Ttm}$ & ND & ND & ND & ND & 35.89 & ND & 11.19 & 0.10 & 16.03 & ND & 0.16 & ND \\
\hline 8 & $\mathrm{Hez}$ & 0.04 & ND & ND & 0.28 & 52.04 & ND & 4.84 & 0.10 & 18.17 & ND & 0.99 & 3.99 \\
\hline 9 & DTm & ND & ND & ND & ND & 12.79 & ND & 0.36 & 0.13 & 12.35 & ND & 0.02 & 0.69 \\
\hline \multirow[t]{2}{*}{10} & FTm & ND & ND & ND & 0.24 & 33.58 & ND & 15.73 & 0.15 & 12.06 & ND & 0.01 & ND \\
\hline & WHO/FAO & 2.0 & 3.0 & 0.01 & 0.05 & - & 0.03 & - & - & $>500$ & 0.05 & 0.20 & 30 \\
\hline
\end{tabular}

WHO/FAO and FEPA values are limits measured in $\mu \mathrm{g} / \mathrm{g}$ per day; ND: not detected

ELEYOWO, OO; AMUSA, OD 
Therefore, caution should be taken in planting areas to ensure that these toxic materials don't find their way into consumed foods. Proper and safe processing activities will also go a long way in ensuring better and safer processed food products for consumption.

Conclusion: The presence of microbial load and some heavy metal contents above permissive level calls for concern in the safety of the tomato products evaluated. There is need for monitoring agencies to create awareness of the possibilities of product contaminant at every level of production, from handling of product to industrial packaging. Agencies should also effectively monitor the production of these processed tomato paste to make sure industries adhere strictly to safety regulations.

\section{REFERENCES}

Adegbola, RA (2013). Comparative analysis of heavy metals in processed tomato paste and fresh tomatoes sold in markets in Ibadan, Nigeria. The Poly. J. Sci. Technol. 8: 53-59.

Adejo, GO; Agbali, FA; Otokpa, OS (2015) Antioxidant, Total Lycopene, Ascorbic Acid and Microbial Load Estimation in Powdered Tomato Varieties Sold in Dutsin-Ma Market. Open Access Lib. $\quad J . \quad$ 2: http://dx.doi.org/10.4236/oalib.1101768

Ademoroti, CMA (1994). Environmental Chemistry and toxicology. 1st Edn. Fodulex Press Ltd. Ibadan, Nigeria.

Adetoro, OA; Bodunde, JG (2015). Yield of Tomato (Lycopersicum esculentum) as influenced by Fertilizer types and Crop spacing. Proceedings of the Eight Annual Conference of the Institute of Ecology and Environmental Studies, Obafemi Awolowo University, Ile-Ife, Nigeria, 194-199 pp.

Akinyele, BJ; Akinkunmi, CO (2012). Fungi associated with the spoilage of berry and their reaction to magnetic field. J. Yeast Fungal Res. 3(4): 49-57.

Bashir, OB; Habib, U; Odunayo, OJ; Opeyemi, AS; Alafe, AH; Owoade, TA (2016). Microorganisms causing post-harvest tomato (Solanum lycopersicum L.) fruit decay in Nigeria. $J$. Entomol. Zool. Stud. 4(1): 374-377.

Buculei, A; Poroch-Seritan, M; Psibilschi, A-M; Rebenciuc, I (2011). Research concerning the evolution of heavy metals content in the fresh and metal can preserved vegetables (tomatoes). In: Katalinic, B (ed) Annals of DAAAM for 2011 and Proceedings of the 22nd International DAAAM Symposium, Vol. 22, No. 1, DAAAM International, Vienna, Austria.

Dallatu, YA; Abechi, SE; Abba, H; Mohammed, US; Ona, EC (2013). Level of heavy metals in fresh and canned foods consumed in North Central Nigeria. Scholarly J. Agric. Sci. 3(6): 210-213.

Dumas, Y; Dadomo, M; Di-Lucca, G; Grolier, P (2003). Effects of environmental factors and agricultural techniques on antioxidant content of tomatoes. J. Sci. Food Agric. 83: 369-382.

Eleyowo, OO; Amusa, OD; Akpan, UU (2016). Prevalent microbes in domestic waters of Iwochang Community, Akwa Ibom, Nigeria. Acad. J. Life Sci. 2(4): 23-28.

Famurewa, JAV; Raji, AO (2011). Physicochemical characteristics of osmotically dehydrated tomato (Lycopersicon esculentum) under different common drying methods. Int. J. Biol. Chem. Sci. 5: 1304-1309.

Fung, DYC (2009). Spoilage, preservation and quality control. Encycl. Microbiol. 54-79.

Ilahy, R; Hdider, C; Lenucci, MS; Tlili, I; Dalessandro, G (2011). Phytochemical composition and antioxidant activity of highlycopene tomato (Solanum lycopersicum L.) cultivars grown in Southern Italy. Scientia Hort. 127: $255-261$.

Juroszek, P; Lumpkin, HM; Yang, RY; Ledesma, DR; $\mathrm{Ma}, \mathrm{C}-\mathrm{H}$ (2009). Fruit quality and bioactive compounds with antioxidant activity of tomatoes grown on-farm: comparison of organic and conventional management systems. J. Agric. Food Chem. 57: 1188-1194.

Kotkov, Z; Lachman, J; Hejtmnkov, A; Hejtmnkov, K (2011). Determination of antioxidant activity and antioxidant content in tomato varieties and evaluation of mutual interactions between antioxidants. LWT - Food Sci. Technol. 44: 17031710 .

Muhammad, S; Shehu, K; Amusa, NA (2004). Survey of the market diseases and aflatoxin contamination of tomato (Solanum lycopersicum 
MILL) fruits in Sokoto North Western Nigeria. Nutr. Food Sci. 34:72-76.

Nagata, M; Yamashita, I (1992). Simple method for simultaneous determination of chlorophyll and carotenoids in tomato fruit. Nippon Shokuhin Kogyo Gakkaish. 39(10): 925-928.

Ray, RC; El Sheikha, AF; Panda, SH; Montet, D (2011) Anti-oxidant properties and other functional attributes of tomato- An overview. Int. J. Food Ferment. Technol. 1(2): 139-148.

Singh, D; Sharma, RR (2007). Postharvest disease of fruit and vegetables and their management. In: Prasad, D. (ed). Sustainable pest management. Daya Publishing House, New Delhi, India. 183$189 \mathrm{pp}$
United States Department of Agriculture (USDA) (2013). Nutrient intakes from food: mean amounts consumed per individual, one day. Accessed April, 2018 from http://www.ars.usda.gov/

Usha, HR; Neena, J; Suvarna, VC; Surendra, HS; Nagaraju, N (2013). Evaluation of Storage Stability Leaf Curl Resistant Cultivars for Producing Dehydrated Tomato. Discourse J. Agric. Food Sci. 1: 1 -7.

Wogu, MD; Ofuase, O (2014). Microorganisms responsible for the spoilage of tomato fruits, Lycopersium esculentum, sold in markets in Benin City, southern Nigeria. Schol. Acad. J. Biosci. 2(7): 459-466. 